\title{
Phosphorus Compartmentalization on the Cellular Level of Douglas Fir Root as Affected by Mn Toxicity: A Synchrotron-Based FTIR Approach
}

\author{
Tanja Dučić, ${ }^{1}$ Jürgen Thieme, ${ }^{2}$ and Andrea Polle ${ }^{3}$ \\ ${ }^{1}$ Hasylab, DESY, Notkestrasse 85, 22607 Hamburg, Germany \\ ${ }^{2}$ NSLS-II, Brookhaven National Laboratory, Upton, NY 11973, USA \\ ${ }^{3}$ Department for Forest Botany and Tree Physiology, Büsgenweg 2, 37077 Göttingen, Germany
}

Correspondence should be addressed to Tanja Dučić, tanja.ducic@ desy.de

Copyright (C) 2012 Tanja Dučić et al. This is an open access article distributed under the Creative Commons Attribution License, which permits unrestricted use, distribution, and reproduction in any medium, provided the original work is properly cited.

\begin{abstract}
We investigated distribution of phosphorus under manganese toxicity in different tissues of $10 \mu \mathrm{m}$ thin-root cross-section of Douglas fir (DF) (Pseudotsuga menziesii) seedlings by using synchrotron-based Fourier transform infrared microscopy (SR-FTIR) as a chemically sensitive imaging method. Manganese is an essential micronutrient in all organisms but may become toxic when present in excess. We found previously that DF variety glauca (DFG) and variety menziesii (DFM) differed in phosphorus uptake, subcellular localization, transport and tissue allocation, as an effect of manganese toxicity. To address the role of $\mathrm{P}$ in seedling tolerance under Mn toxicity, we determined $\mathrm{P}$ allocation in different root tissues. In DFG, but not in DFV, the P concentration was kept at a constant level even under Mn toxicity. Earlier X-ray microanalysis showed Mn accumulation in epidermal and cortical cells of both varieties after Mn treatment, suggesting that the root endodermis was a barrier for Mn to protect the vascular system and shoot from high Mn, with possible role of $\mathrm{P}$ ameliorations. Here, we discuss the potential role of $\mathrm{P}$ in $\mathrm{Mn}$ compartmentalization and toxicity tolerance in two different varieties.
\end{abstract}

Keywords: Synchrotron-based FTIR, plant tissue, phosphorus, manganese toxicity

\section{Introduction}

Manganese (Mn) is an essential nutrient element necessary for activation of a wide range of enzymes. To fulfil its metabolic functions, $\mathrm{Mn}$ is only required at low concentrations. Plant availability of Mn depends on soil properties, mostly $\mathrm{pH}$, and on root exudates for $\mathrm{Mn}$ chelation or reduction. In general, excess $\mathrm{Mn}$ causes disorders of normal plant metabolism. Therefore, Mn-homeostasis on the cellular level is strictly regulated [1]. Two main varieties of Douglas fir (Pseudotsuga menziesii) var. menziesii (DFM) and $P$. menziesii var. glauca (DFG) differ in Mn sensitivity, that is, DFG but not DFM showed symptoms of Mn toxicity, when exposed to excess Mn [2, 3]. 
Our previous results revealed different transport and translocation properties of $\mathrm{Mn}$ into different subcellular compartments for the two varieties of Douglas fir [1,3]. The Mn-resistant variety DFM showed Mn retention in the root system and entrapment of Mn in electron-dense precipitates ("black bodies"), containing extremely high Mn concentrations, together with Ca and P [2]. In contrast to the DFM, the Mn-susceptible variety transported a higher fraction aboveground to photosynthetically active tissues [3]. Beside these differences, DFG and DFM also vary in P accumulation within the plant tissues. Phosphorus-limited DFM, but not DFG, seedlings were less Mn-susceptible [2]. This suggests that P plays an important role in mediating Mn tolerance. However, the tissue distribution of phosphorus in response to $\mathrm{Mn}$ stress is not known. To address $\mathrm{P}$ localization in roots tissues under conditions of $\mathrm{Mn}$ stress, we performed the synchrotron-based FTIR analyses on thin-root cross-section.

Synchrotron-based FTIR spectromicroscopy is a useful tool for imaging the organic compounds in different cells, without any staining/labeling or cutting artifacts, as shown before [4-6]. The contrast of this imaging technique is based on the local density of vibrational states characteristic for functional molecular groups [7]. Synchrotron radiation is certainly the most useful source for IR, as it is a "white" source with a flat broadband distribution over the entire infrared spectral range (from far-IR to near-IR) [8]. The high brightness compared to conventional laboratory sources $[8,9]$ opens up the opportunity to combine the highest spectral resolution with a spatial resolution at the diffraction limit $[7,8]$.

\section{Material and Methods}

\subsection{Sample Preparation}

Plants were grown hydroponically in standard medium, containing two different $\mathrm{Mn}$ concentrations in $\mathrm{Mn}^{2+}$ form (as described in [2]). In short, 2-weeks-old seedlings were exposed for two additional weeks to $5 \mu \mathrm{M} \mathrm{Mn}$ (control) or $5 \mathrm{mM} \mathrm{Mn}\left(\mathrm{Mn}_{2} \mathrm{SO}_{4}\right)$. After 2 weeks, plants were sampled for analyses. Roots tips, from intact seedlings, were rapidly frozen in a tissue freeze medium (Leica 020108926, Jung, Germany) loaded in $5 \mathrm{~mm}$-long gelatin capsules and cooled with liquid nitrogen to $-196^{\circ} \mathrm{C}$. Frozen blocks $5 \mathrm{~mm}$ behind the root tip were directly cut with a cryomicrotome (Reichert-Jung, Model 2800 Frigocut N). Ten $\mu \mathrm{m}$ cross-sections were mounted on the MirrIR low-e microscope slides for reflective infrared studies without interfering absorption in the range from 4000 to $400 \mathrm{~cm}^{-1}$ (Kevley Technologies, USA), freeze-dried at $-70^{\circ} \mathrm{C}$ for two days, and adjusted to room temperature by increasing the temperature slowly up to $20^{\circ} \mathrm{C}$ during the next two days. The specimens were stored in a desiccator over silica gel at room temperature.

\subsection{Synchrotron-Based FTIR Analysis}

The FTIR measurements were carried out at the FTIR spectromicroscopy station of ID21 at European Synchrotron Radiation Facility (ESRF) synchrotron facility. The IR spectromicroscopic maps were collected in reflection mode using an Infrared microscope (Thermo Nicolet Nexus) coupled to a FTIR spectrometer (Thermo Nicolet Continuum). The IR microscope is equipped with a motorized sample stage and a liquid nitrogen cooled mercury cadmium telluride (MCT) detector. Most of the analysis and maps were collected with a pixel size of $5 \times 5 \mu \mathrm{m}^{2}$ and step size of $2 \mu \mathrm{m}$, and each spectrum was acquired with 64 accumulations at $4 \mathrm{~cm}^{-1}$ spectral resolution. 


\section{Results}

Areas of $300 \mu \mathrm{m} \times 300 \mu \mathrm{m}$ were mapped in DFG and DFM root tissues with full high resolution, and spectra were recorded for each pixel by the SR-FTIR spectromicroscope. Data was collected on a freezedried sample in reflection mode, at the settings described above. 2D images can then be generated for all relevant FTIR absorption lines by representing the spectral characteristics of region of interest, such as fingerprint peak areas of the molecular groups on a colour scale.

The phosphate and/or phosphine oxide (Pi) groups in the spectra show strong bands at around $1100 \mathrm{~cm}^{-1}$. Two bands may be associated with the asymmetric and symmetric $\mathrm{PO}^{-2}$ stretching bands at 1236 and $1086 \mathrm{~cm}^{-1}$, respectively, the first with $\mathrm{CH}_{2}$ scissor vibration or the $\mathrm{CH}_{3}$ asymmetric bend vibration [10]. On the other hand, FTIR bands around $1100-1000 \mathrm{~cm}^{-1}$ in some plants contributed also by alcoholic and polysaccharide compounds present in the tissues [11].

Figures 1(A), 1(a), 1(D) and 1(d) shows the 2D and 3D images of control and Mn-exposed DFM root cross-sections, generated for phosphate and phosphine oxide groups (a strong band at $1100 \mathrm{~cm}^{-1}$ associated with $\mathrm{P}-\mathrm{O}$ bonds of phosphate), respectively. The scanning regions of interest (ROI) were chosen to include the central cylinder, endodermis, cortex, and epidermis to acquire the spectromicroscopic maps, based on the inline (coaxial) visible light optical microscope Figures 1(B) and $1(b)$.

Cumulative FTIR absorption spectra of a $10 \mu \mathrm{m}$ cross-sections of root tip of a control and a Mn-treated DFM plant are shown in Figures 1(C) and 1(c), respectively. Mn-treated plants showed P accumulation in the cortical, endodermal, and central cylinder cells, besides the epidermis as in control plants.

The band at $1270 \mathrm{~cm}^{-1}$, which has been assigned to guaiacyl lignin [12] was also dominant in spectra of both Mn- and un-treated plants. Lignin bands at $1265 \mathrm{~cm}^{-1}$ and $1311 \mathrm{~cm}^{-1}$ are very pronounced since lignin content in wood is around $20 \%$ [13]. Towards higher wavenumbers, the next pronounced features in the spectra are the amide I and amide II absorption bands, exhibiting peaks at 1656 and $1550 \mathrm{~cm}^{-1}$, respectively, corresponding to vibrations of the protein backbone [8]. The integrated peak intensity of the amide bands can serve as a measure for the local protein concentration. The peaks indicative of proteins are superimposed by cellulose since there are very close to the cellulose peak at $1635 \mathrm{~cm}^{-1}$ [5].

Figure 2 shows the Pi groups 2D and 3D images generated from FTIR absorption lines, for control and Mn-treated DFG plants (A, a, D, and d, resp.). The scanning regions of interest (i.e., central cylinder, endodermis, cortex, and epidermis as for DFM analysis (Figure 1)) are based on the inline visible light optical microscope (Figures 2(B) and 2(b)). Cumulative FTIR absorption spectra of a $10 \mu \mathrm{m}$ crosssections of root tip of control and treated plant DFG plant show very similar $\mathrm{P}$ distribution in the entire root tissues, that is, Mn stress did not affect $\mathrm{P}$ compartmentalization (Figures 2(C) and 2(c)).

\section{Discussion}

Synchrotron-based FTIR microscopy study of thin cross-section of root tissues of DF is presented in this study. The emphasis was on phosphorus mapping by using FTIR spectromicroscopy. Up to now, only a few in situ studies of elemental distributions in DF samples have been performed, mainly by electron microscopy-based X-ray microanalysis (EDX) $[2,14]$. While electron microscopy requires 


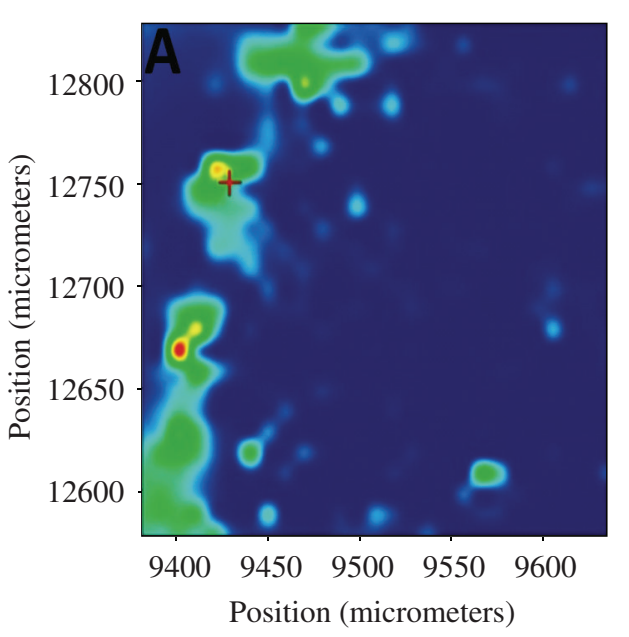

(A)

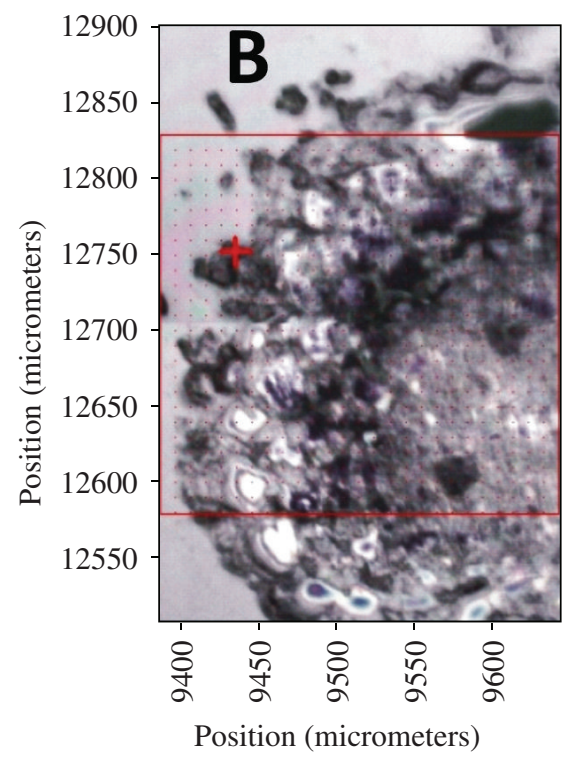

(B)
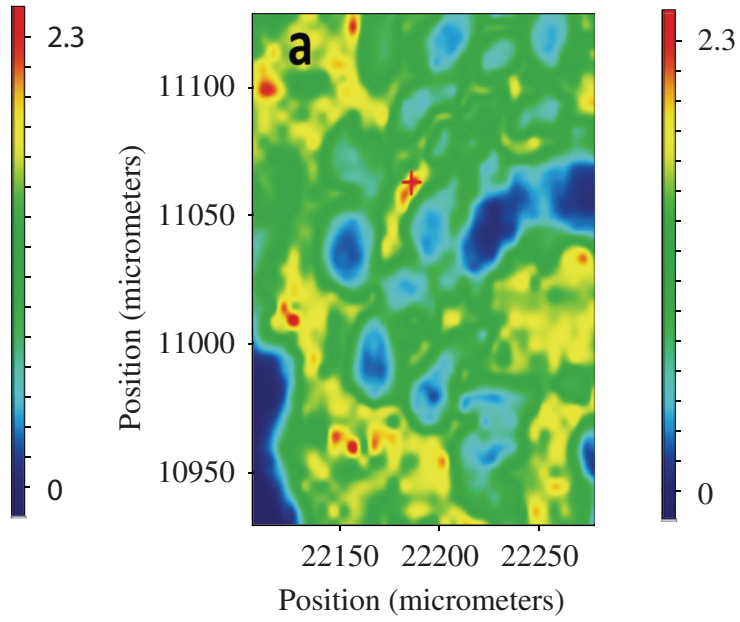

(a)

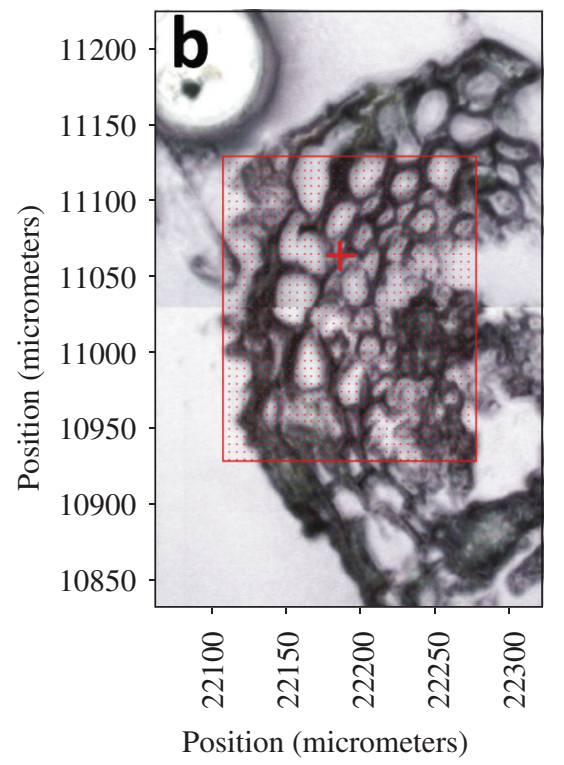

(b)

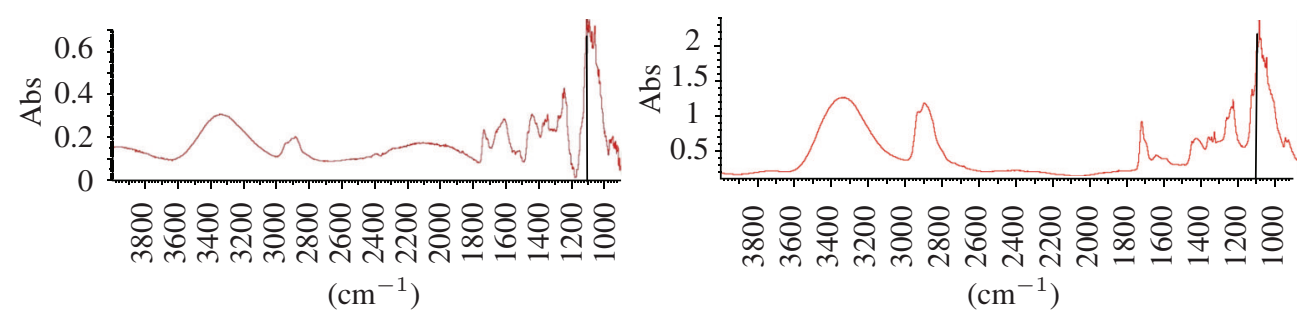

(C)

(c)

Figure 1: Continued. 


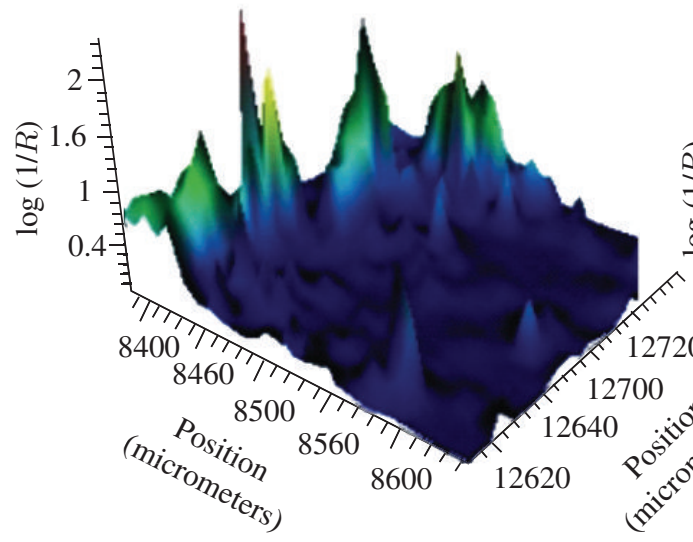

(D)

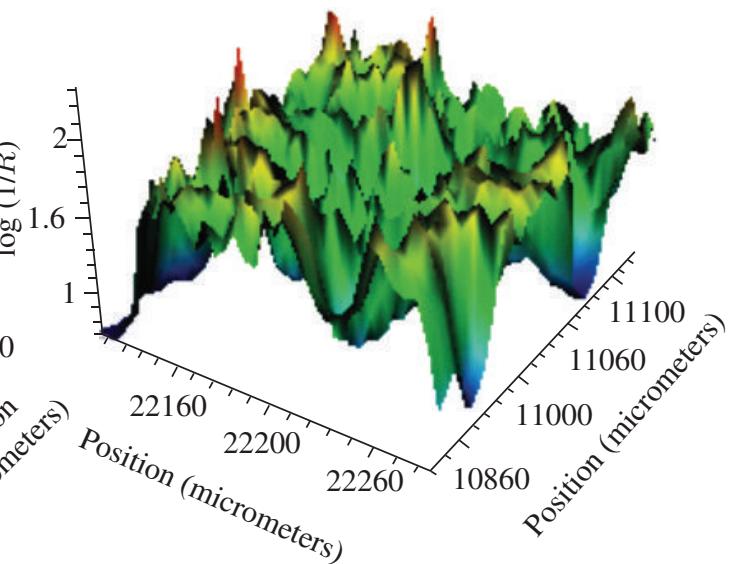

(d)

Figure 1: ((A), (a)) Synchrotron-based FTIR microscopy of $10 \mu \mathrm{m}$-thick freeze-dried roots cross-section of Douglas fir var. menziesii of control and $5 \mathrm{mM}$ Mn-treated plants, respectively. The scanned regions of interest for the spectromicroscopy maps were chosen from online visible microscopic pictures (marked with the red rectangle in (B), (b)). An area was mapped with full high-resolution spectra in each pixel. $2 \mathrm{D}((\mathrm{A}),(\mathrm{a}))$ and $3 \mathrm{D}((\mathrm{D}),(\mathrm{d}))$ images were generated for the absorption line of phosphorus group $(\mathrm{P}=\mathrm{O}$, phosphate and phosphine oxide) at $1100 \mathrm{~cm}^{-1}$. The cumulative FTIR absorption spectra of freeze-dried roots sections as recorded in reflection mode by the SR-FTIR spectromicroscope of ID21 at ESRF are shown in $(\mathrm{C})$ and $(\mathrm{c})$.

invasive sample preparation, typically including fixation before thin slicing of the sample, FTIR can provide spectra without risk of changing the cell organization by chemical fixation.

FTIR spectromicroscopy clearly revealed Pi peaks in the roots of DFM (Figure 1) and DFG (Figure 2). This distribution correlates well with Mn compartmentalization after synchrotron-based Xray fluorescence analysis (data not shown). FTIR analysis, which shows Pi-compounds maps in entire cross-sections of roots, provides a better overview of the total P locations (Figures 1 and 2). After Mn stress, phosphorus redistribution towards central cylinder was found in DFM (Figure 1), but not in the susceptible variety DFG (Figure 2). DFG seedlings kept a uniform distribution of P across all root tissues, in control as well as in Mn-treated plants. The redistribution of P after Mn stress, which was only observed in roots of DFM, has likely enhanced the Mn tolerance of this variety since $\mathrm{P}$ relocation in the tissues probably binds the surplus $\mathrm{Mn}$, and in this way protects the vascular system and shoot from Mn toxicity.

Notably FTIR spectromicroscopy infers information on protein secondary structure by averaging locally over all proteins in the excitation volume. The spatial distribution of the proteins at $1635 \mathrm{~cm}^{-1}$, which is distinctly different from that one of lipids, is superimposed on the cellulose peak (Figures 1(C), 1(c), 2(C), and 2(c)). The observed positions of the amide band peaks were predominantly due to beta-sheet conformations, and they differ in DFM and DFG as well as in response to Mn treatment. Differences are also observed at the following wavenumbers: at $1245 \mathrm{~cm}^{-1}$, where they originate from $\mathrm{C}-\mathrm{O}-\mathrm{H}$ asymmetric deformation vibration of hemicellulose and cellulose [5], then at $1420 \mathrm{~cm}^{-1}$, which is associated with $\mathrm{C}-\mathrm{H}$ bends from asymmetric $\mathrm{CH}_{3}$ group of cellulose, lipids and polysaccharides, as well as at $1740 \mathrm{~cm}^{-1}$, from $\mathrm{C}=\mathrm{O}$ stretching alkyl group of esterified pectins and lipids. The symmetric 


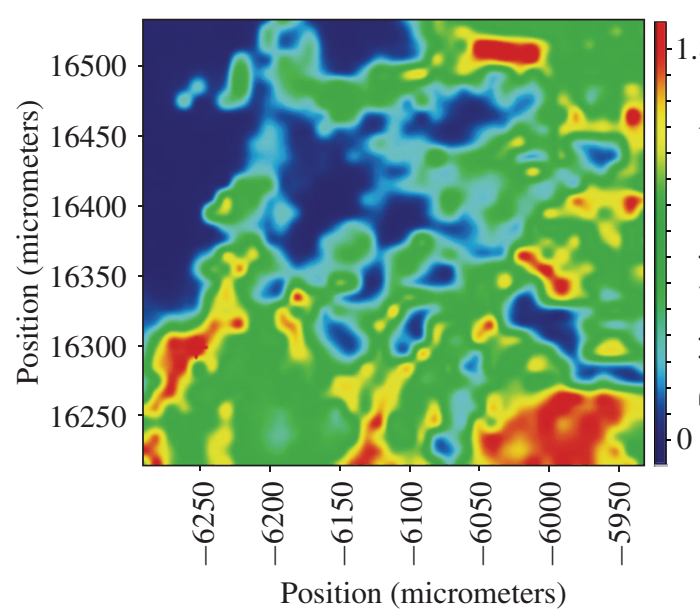

(A)

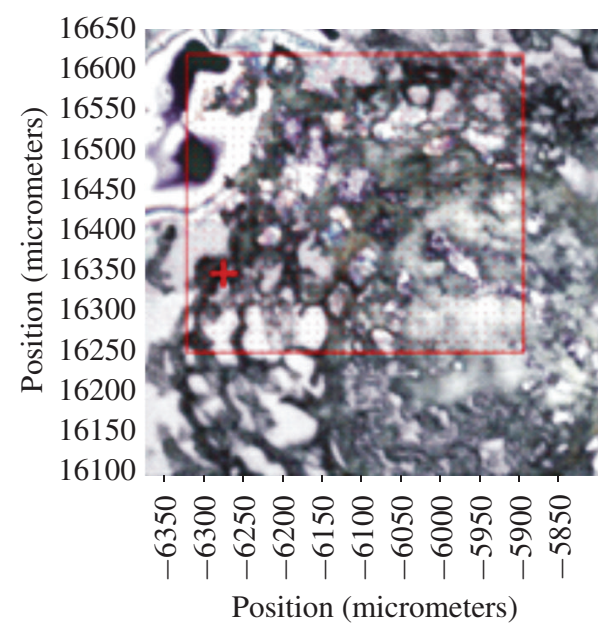

(B)

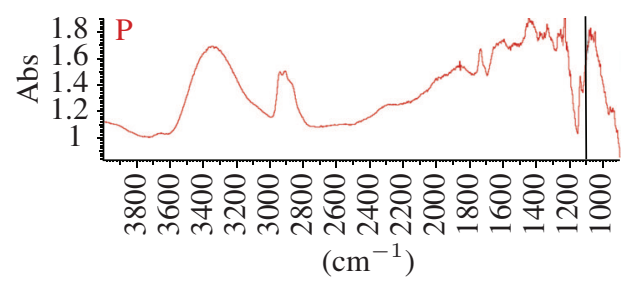

(C)

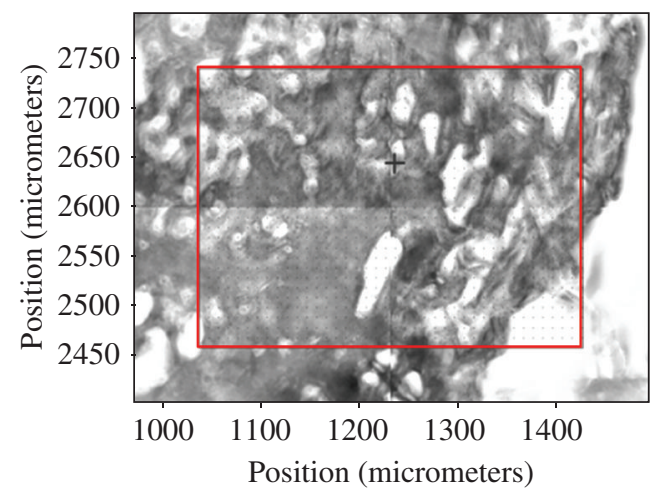

(b)

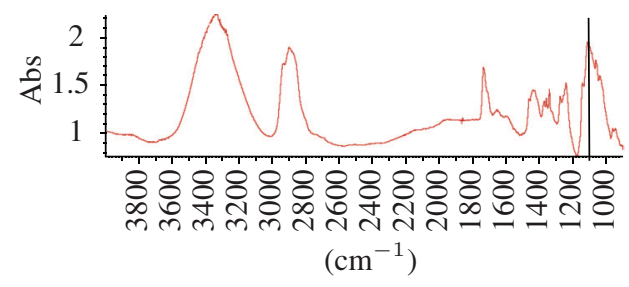

(c)

Figure 2: Continued. 


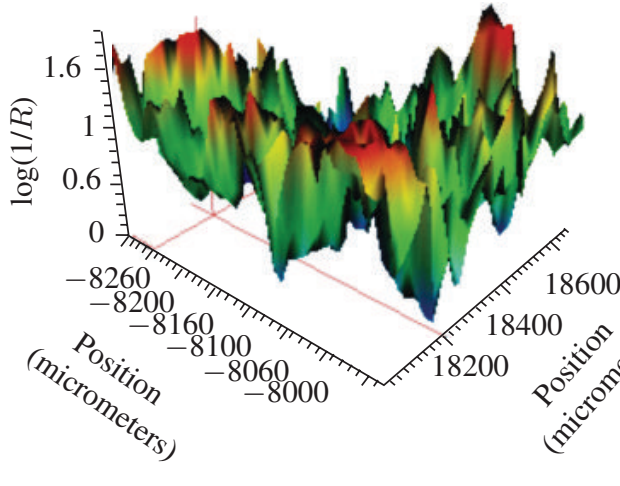

(D)

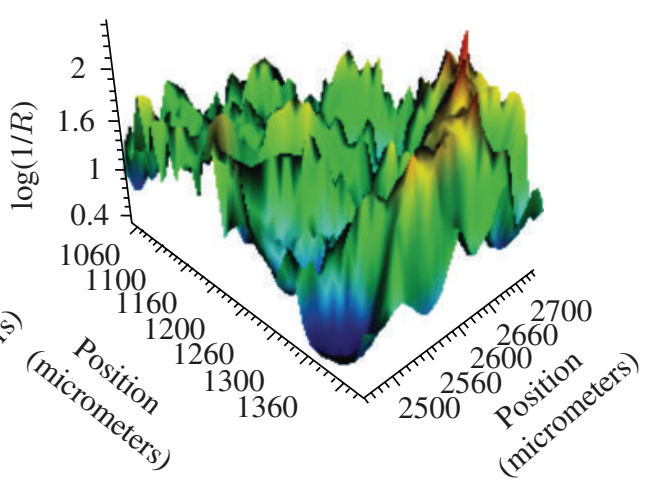

(d)

Figure 2: ((A), (a)) Synchrotron-based FTIR microscopy of $10 \mu \mathrm{m}$-thick freeze-dried roots cross-section of Douglas fir var. glauca of control and $5 \mathrm{mM}$ Mn-treated plants, respectively. The scanned regions of interest for the spectromicroscopy maps were chosen from online visible microscopic pictures (marked with the red rectangle in (B), (b)). An area was mapped with full high-resolution spectra in each pixel. $2 \mathrm{D}((\mathrm{A}),(\mathrm{a}))$ and 3D ((D), (d)) images were generated for the absorption line of phosphorus group (P=O, phosphate and phosphine oxide) at $1100 \mathrm{~cm}^{-1}$. The cumulative FTIR absorption spectra of freeze-dried roots sections as recorded in reflection mode by the SR-FTIR spectromicroscope of ID21 at ESRF are shown in $(\mathrm{C})$ and $(\mathrm{c})$.

and asymmetric $\mathrm{CH}_{2}$ stretching of lipid bands at 2850 and at $2925 \mathrm{~cm}^{-1}$, respectively [5] also changes after Mn treatment in DFM and DFG, which is underlying the complex changes of all biomolecules on the cellular level in both varieties under Mn stress.

\section{Acknowledgments}

The authors thank to Dr. Margaret Rak for FTIR microscopy introduction and critical reading of the paper, Dr. Andrea Olbrich for helpful suggestions during the sample preparation and Christine Kettner for the plants growing. The European Synchrotron Radiation Facility (ESRF) in Grenoble is acknowledged for beam time allocation and excellent working conditions.

\section{References}

[1] T. Dučić and A. Polle, "Transport and detoxification of manganese and copper in plants," Brazilian Journal of Plant Physiology, vol. 17, no. 1, pp. 103-112, 2005.

[2] T. Dučić and A. Polle, "Manganese toxicity in two varieties of Douglas fir (Pseudotsuga menziesii var. viridis and glauca) seedlings as affected by phosphorus supply," Functional Plant Biology, vol. 34, no. 1, pp. 31-40, 2007.

[3] T. Dučić, L. Leinemann, R. Finkeldey, and A. Polle, "Uptake and translocation of manganese in seedlings of two varieties of Douglas fir (Pseudotsuga menziesii var. viridis and glauca)," New Phytologist, vol. 170, no. 1, pp. 11-20, 2006. 
[4] L. P. Choo, D. L. Wetzel, W. C. Halliday, M. Jackson, S. M. LeVine, and H. H. Mantsch, "In situ characterization of $\beta$-amyloid in Alzheimer's diseased tissue by synchrotron Fourier transform infrared microspectroscopy," Biophysical Journal, vol. 71, no. 4, pp. 1672-1679, 1996.

[5] K. M. Dokken and L. C. Davis, "Infrared imaging of sunflower and maize root anatomy," Journal of Agricultural and Food Chemistry, vol. 55, no. 26, pp. 10517-10530, 2007.

[6] T. Dučić, S. Quintes, K. A. Nave et al., "Structure and composition of myelinated axons: a multimodal synchrotron spectro-microscopy study," Journal of Structural Biology, vol. 173, no. 2, pp. 202-212, 2011.

[7] M. Diem, M. Romeo, C. Matthäus, M. Miljkovic, L. Miller, and P. Lasch, "Comparison of Fourier transform infrared (FTIR) spectra of individual cells acquired using synchrotron and conventional sources," Infrared Physics and Technology, vol. 45, no. 5-6, pp. 331-338, 2004.

[8] P. Dumas and M. J. Tobin, "A bright source for infrared microspectroscopy: synchrotron radiation," Spectroscopy Europe, vol. 15, no. 6, pp. 17-23, 2003.

[9] W. D. Duncan and G. P. Williams, "Infrared synchrotron radiation from electron storage rings," Applied Optics, vol. 22, no. 18, pp. 2914-2923, 1983.

[10] M. Szczerbowska-Boruchowska, P. Dumas, M. Z. Kastyak et al., "Biomolecular investigation of human substantia nigra in Parkinson's disease by synchrotron radiation Fourier transform infrared microspectroscopy," Archives of Biochemistry and Biophysics, vol. 459, no. 2, pp. 241-248, 2007.

[11] Z. He, J. Mao, C. W. Honeycutt, T. Ohno, J. F. Hunt, and B. J. Cade-Menun, "Characterization of plant-derived water extractable organic matter by multiple spectroscopic techniques," Biology and Fertility of Soils, vol. 45, no. 6, pp. 609-616, 2009.

[12] D. Fengel and G. Wegener, Wood, Chemistry and Ultrastructure and Reactions, Kassel, Ramagen, Germany, 2003.

[13] R. Rana, R. Langenfeld-Heyser, R. Finkeldey, and A. Polle, "FTIR spectroscopy, chemical and histochemical characterisation of wood and lignin of five tropical timber wood species of the family of Dipterocarpaceae," Wood Science and Technology, vol. 44, no. 2, pp. 225-242, 2010.

[14] T. Dučić, D. Berthold, R. Langenfeld-Heyser, F. Beese, and A. Polle, "Mycorrhizal communities in relation to biomass production and nutrient use efficiency in two varieties of Douglas fir (Pseudotsuga menziesii var. menziesii and var. glauca) in different forest soils," Soil Biology and Biochemistry, vol. 41, no. 4, pp. 742-753, 2009. 


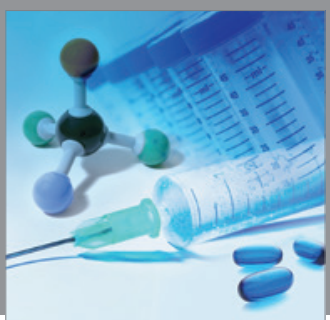

International Journal of

Medicinal Chemistry

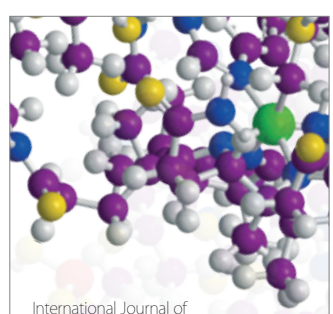

Carbohydrate Chemistry

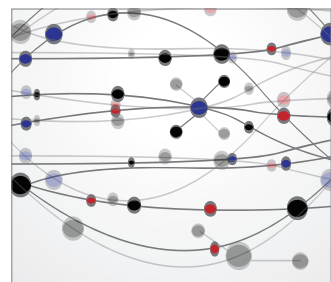

The Scientific World Journal
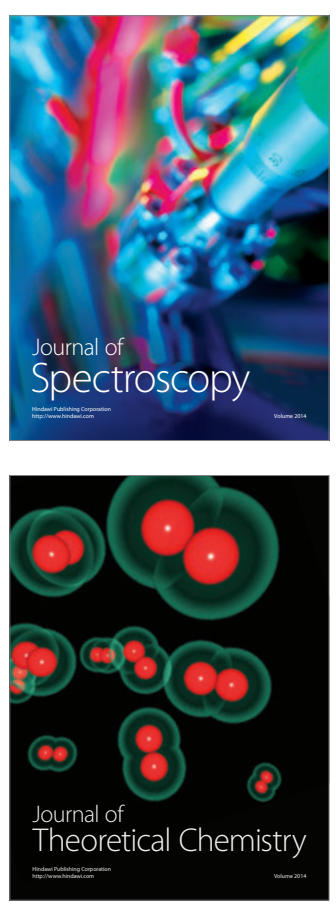
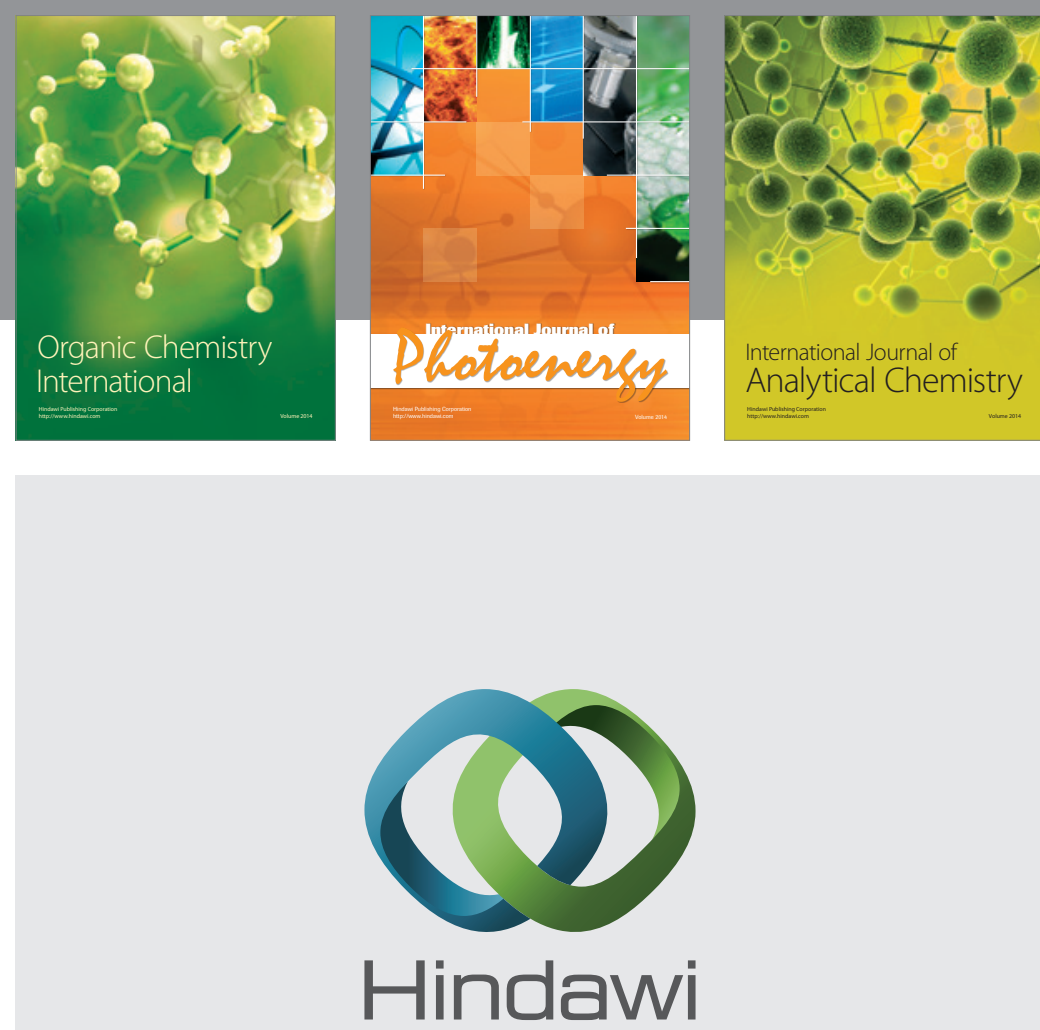

Submit your manuscripts at

http://www.hindawi.com
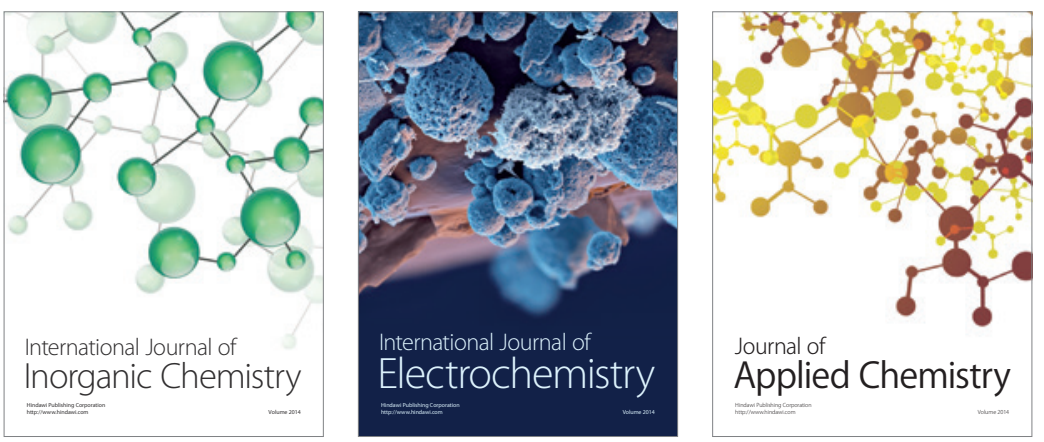

Journal of

Applied Chemistry
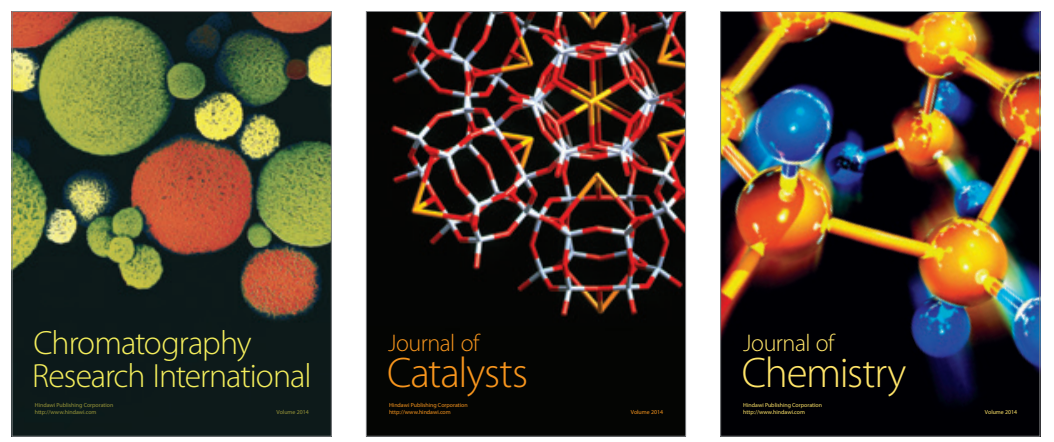
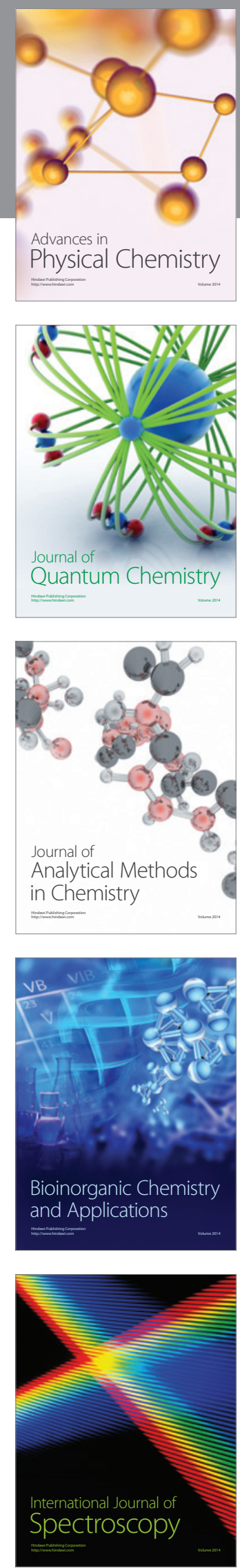